\title{
Economic Costs and Benefits of EMU Membership from the Perspective of a Non-member
}

\author{
Emilia Gyoerk ${ }^{1}$
}

Published online: 7 October 2017

C) The Author(s) 2017. This article is an open access publication

\begin{abstract}
The result of the decision whether to join the European Monetary Union, an irreversible policy choice for several European Union members, presents potentially significant costs and benefits. With a focus on the largest EU economy outside of the euro, Sweden, this paper applies the novel synthetic control method of estimation to evaluate whether there are costs or benefits associated with EMU membership in terms of various aspects of economic performance and how these have developed from 1999 to 2015. Findings indicate that Sweden would have borne non-negligible costs from currency union membership, exemplified by around $10 \%$ lower productivity, exports, investment, and consumption, and $8 \%$ greater government expenditure and imports on a yearly basis since the introduction of the euro, leading to significant cumulative reductions in potential economic activity. The robust results suggest costs may be persisting and in some cases growing in magnitude.
\end{abstract}

Keywords European Monetary Union · Sweden · Synthetic control method

JEL Classifications $\mathrm{C} 33 \cdot \mathrm{F} 15 \cdot \mathrm{F} 45 \cdot \mathrm{O} 52$

\section{Introduction}

The result of the decision whether to join the European Monetary Union, an irreversible policy choice for several European Union members, presents significant costs and benefits. Benefits include reduced exchange rate volatility, trade uncertainty, and relative price variability; harmonisation of interest rates; and increased welfare from augmented international competition (Eichengreen 1990). Costs include loss of independent monetary and budgetary policies and thereby the ability to combat

Emilia Gyoerk

Emilia.Gyork@gmail.com

1 Department of Economics, University of Warwick, Coventry CV4 7AL, UK 
idiosyncratic shocks and smooth business cycles, as well as inhibiting currency devaluation to bolster competitiveness (Feldstein 1997 and De Grauwe 2013, 2016).

Although legally committed to adopt the common currency, several countries postpone or opt out of this obligation. Advanced economies like the United Kingdom and Denmark negotiated explicit exemption agreements, while others such as Sweden and Poland do not fulfil certain convergence criteria and therefore remain noncompliant with their Treaties of Accession. ${ }^{1}$ The only outstanding convergence criteria by which Sweden does not comply is membership in ERM II. However, even though the Swedish krona is officially in free float, it has in effect remained closely aligned with the euro. Figure 1 shows the exchange rate of the SEK against the EUR since the inception of the common currency. Although an arbitrary central exchange rate corresponding to the one prevalent on January 1, 1999 is used as a reference anchor, one can see that even with modification to this central rate, the SEK remains comfortably within the envisioned $15 \%$ band, with the exception of a slight deviation in 2009. Therefore, as ERM II membership is the only formal condition preventing Swedish EMU membership, official adherence to this exchange rate regime appears readily implementable.

Given the relative ease with which Sweden could join the monetary union in addition to its current stance, following the British referendum to leave the EU, as the largest EU economy outside of the Euro Area it makes for an interesting case to study the hypothetical implications of EMU membership. Compared to some other prospective joining countries, Sweden also presents the opportunity to assess potential implications of currency union accession for a relatively more economically advanced non-member. Using the novel synthetic counterfactual method of estimation, it is found that Sweden would have borne non-negligible costs from EMU membership, exemplified by around $10 \%$ lower productivity, exports, investment, and consumption, as well as $8 \%$ greater government expenditure and imports on a yearly basis since the introduction of the euro, leading to significant cumulative reductions in potential economic activity.

Having regard to the growing literature highlighting shortcomings of the EMU, it may be that the estimated costs associated with membership are due to these shortcomings, or "design flaws" (De Grauwe 2013). However, given significant recent reforms and implementation of policies and institutions such as the Banking Union, the European Stability Mechanism, as well as the Single Supervisory Mechanism and Single Resolution Mechanism, some of these shortcomings have been corrected such that the net balance of economic costs and benefits of EMU membership may have shifted. Assessment of whether these recent measures have been successful in resolving the shortcomings and support net economic benefits of currency union membership remains for future research.

The paper is organised as follows. The next section describes the primary flaws of the EMU that may have contributed to the costs observed for Sweden, some empirically found benefits of EMU membership, and a review of relevant counterfactual analyses. The third section introduces and motivates the methodology. The fourth section presents the main results, and the fifth section inference and robustness tests. The sixth section concludes.

\footnotetext{
${ }^{1}$ For a detailed description of convergence assessments for euro adoption see the convergence reports of the European Commission: //ec.europa.eu/economy_finance/euro/adoption/convergence_reports/index_en.htm.
} 


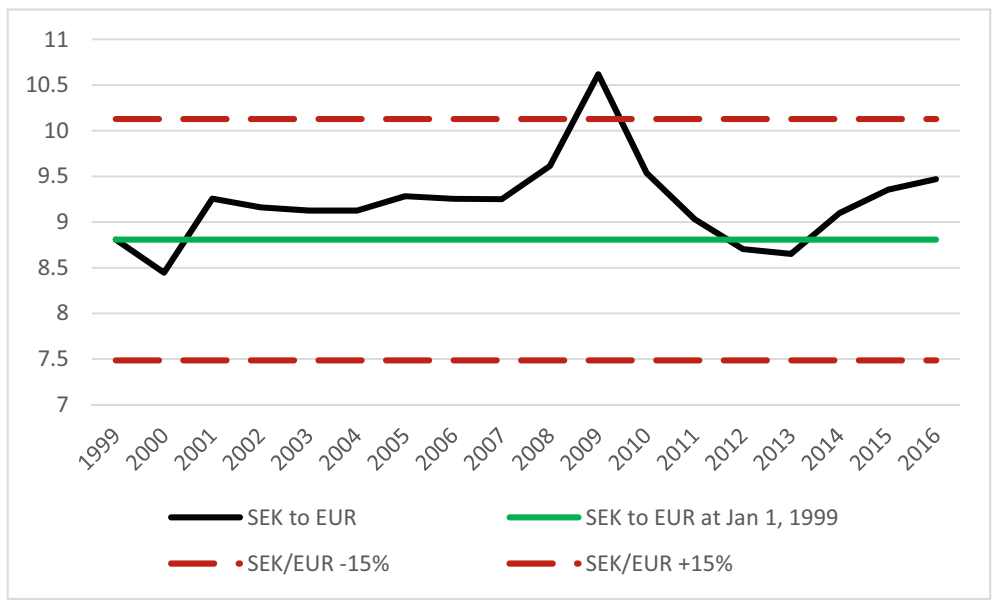

Source: European Central Bank Statistical Data Warehouse, retrieved April 1, 2017.

Fig. 1 The SEK/EUR exchange rate with $15 \%$ bands around its 1999 level

\section{Motivation and Previous Literature}

One may generally define three strands of flaws of the European Monetary Union: first, the absence of a common fiscal policy; second, the application of a single monetary policy without a mechanism to promote business cycle convergence among member states; and third, the failure to oversee financial stability.

Firstly, although there was awareness of the necessity for fiscal policy coordination and discipline, which led to the provisions contained in preventive measures such as the Maastricht criteria and the Stability and Growth Pact, the euro project lacked an effective mechanism for their enforcement (Durré et al. 2014). As a result, EMU membership became associated with perceived protection from risk for sovereigns, which lead to risk mispricing by market participants, allowing countries to access cheaper borrowing terms.

Various explanations for this mispricing are given. Hannoun (2011) argues that the underestimated risks observed during 1999-2011 fit into a general long-term trend of financial market sovereign risk pricing: periods of complacency, characterised by unusually low risk perceptions and compressed spreads, occur while risks accumulate and are followed by a stark market correction as interest rate spreads diverge widely. Among academic contributions, Bianchi (2016) indicates that risk pricing failed to consider the state of the external indebtedness of the economy in periods of low global uncertainty, similarly to Giordano et al. (2013) who suggest that mispricing occurred as market participants remained (at least partially) ignorant to macroeconomic fundamentals when pricing sovereign risks. Arghyrou and Kontonikas (2012) pose that sovereign risk mispricing was supported by the perception of currency union membership irreversibility as well as mutualisation of fiscal debts, and that only after the events of the Greek crisis did market expectations shift away from these two convictions. Frankel (2013) argues that the compression of risk premia occurred due to markets maintaining an expectation of ECB bailouts to troubled countries, despite the "no bailout" clause embedded in the euro foundation. 
However the perception of reduced sovereign risk emerged, it allowed repeated violation of the Maastricht criteria without substantial punitive action or remedy, and indeed, lax fiscal policies were present in several countries. For example, Greece never posted a budget deficit below the envisaged 3\% threshold nor did the debt-to-GDP ratio ever decline from 100\% (reported in 1993) toward the 60\% limit (Frankel 2013). The situation precipitated when the crisis called for public intervention and, thus, public debts exploded. Although beyond the scope of this paper to discuss the implications of EMU membership on public debt burden, results of this study indicate that Sweden would have reported $11 \%$ greater government expenditure in 2008 as a currency union member, which would have needed to be financed either by politically painful fiscal measures or by increased accumulation of public debt. Without credible fiscal controls, the politically favourable choice is likely the latter option.

With regard to the second strand of flaws, according to the theory on Optimum Currency Areas, the overall net benefits of a common currency are increasing in the degree of business cycle synchronisation among member economies (Mundell 1961). A shared monetary policy will not be optimal for all countries involved if their business cycles are considerably divergent. Indeed, common monetary policy can in this case exacerbate the business cycle fluctuations of union participants by on one hand being insufficiently accommodative for a member state approaching a trough while on the other hand not being tight enough for a booming economy, leading to even stronger boom and bust dynamics. De Grauwe and Ji (2015) expand this argument further by stating that EMU membership does little to promote the convergence of business cycles within the union.

The literature appears divided on whether European business cycles are converging, and it seems that Europe has undergone periods of both convergence and divergence (Massmann and Mitchell 2004). Earlier studies suggest convergence occurred especially since the 1980s, and there is support for the argument that currency union membership, by promoting trade, endogenously contributes to business cycle convergence within the monetary union. ${ }^{2}$ Although confirming the finding of increased synchronisation also in the early 1990s, De Haan et al. (2008) find that significant desynchronisation remains, without convergence toward a 'European' business cycle. Aguiar-Conraria and Soares (2011) add support to this conclusion in finding that Portugal, Greece, Ireland, and Finland do not show statistically relevant degrees of synchronisation with Europe, nor do recent Euro members Slovakia and Cyprus. Furthermore, Pentecôte et al. (2015) conduct a study on the impact of trade integration on business cycle convergence among the original eleven euro area countries and find that new trade flows have a negative impact on cycle synchronisation.

A second potential consequence of implementing a shared monetary policy is related to the unique exchange rate, or in other words, the linkage to competitiveness. In the absence of nominal exchange rate flexibility, cross-border imbalances require an economy that suffers from slacking competitiveness to undergo painful internal revaluation through its price level, which can spark a debt-deflation spiral with serious consequences. The economic divide between the southern and northern European countries has become most apparent in the aftermath of the great recession, when the

\footnotetext{
${ }^{2}$ See for example Artis et al. 2004; Böwer and Guillemineau 2006; and for the endogeneity argument see Frankel and Rose 1998.
} 
latter group experienced higher economic growth and price level gains compared to the former group, in which recessionary and deflationary pressures have been more persistent (for example Sinn and Valentinyi 2013).

The third strand of flaws, regarding oversight of financial stability and bank supervision, received only limited attention, as noted by Begg et al. (1991), and was not operationally addressed until well into the establishment of the monetary union. Indeed, to centralise bank supervision at the European level was not expected to become a necessity at first, with close cooperation of the ECB and national competent authorities responsible for bank supervision forecasted as sufficient (Padoa-Schioppa 1999). However, as noted during the recent financial crisis, when the lack of sufficient bank supervision and regulation lead to excessive accumulation of credit alongside diminishing loan quality, the effects on financial stability can be disastrous. Giavazzi and Wyplosz (2015) point out that delaying the appointment of responsibility for bank supervision had serious consequences: drawing a parallel to how the financial crisis was mitigated in the United States, they argue that by first addressing the problems in the banking sector through TARP (Troubled Asset Relief Program) and then proceeding to deploy macroeconomic tools, the US was able to significantly shorten the crisis compared to Europe where the initially applied monetary policy measures were rendered less effective by an impeded credit channel.

We now turn to the potential benefits of joining the EMU, starting with Micco et al. (2003) who estimate the effects of membership on trade among members and nonmembers. EMU membership has a ceteris paribus augmenting effect on trade among members of around $10-15 \%$, in addition to a positive spillover effect of increasing trade among members and non-members by $8 \%$. This suggests the EMU functions as an overall catalyst to trade, which is not limited to bilateral trade within the union. In the case of Sweden, the authors postulate trade with EMU member states would have been $11 \%$ higher by 2001 if Sweden had joined the monetary union.

A decade following the initial Calmfors Commission investigation (Calmfors et al. 1996) into the advantages and disadvantages of Swedish EMU membership, Söderström (2008) revisits the evaluation with updated data until 2005. Using a DSGE model in a VAR analysis, different counterfactual exercises are conducted to analyse the development of economic indicators in a setting mimicking the prevailing conditions of currency union membership. When incorporating monetary policy shocks, an unambiguous interpretation in favour of EMU membership is found.

Pesaran et al. (2007) apply an alternative counterfactual approach to the question of how EMU membership would have affected output and the price level in the United Kingdom and Sweden. Unlike the typical counterfactual analysis contrasting a counterfactual to the actual trend, this method compares two counterfactuals; one with the restriction of fixing short-term interest rates and exchange rates, simulating EMU membership, and one without, thus avoiding the problem of disentangling treatment effects from forecasting errors. The authors find that both the UK and Sweden would have had lower interest rates and higher output as currency union members.

The synthetic control method (SCM), first introduced by Abadie and Gardeazabal (2003) does not rely on forecasts of the counterfactual, rather it constructs the counterfactual using real time data based on statistical matching. Recently, there has been interesting applications of the SCM to cost and benefit analyses of policy programmes, including the common currency. Manasse et al. (2014) examine the impact of EMU 
membership on various aspects of the Italian economy and find considerable costs in terms of subdued labour productivity. As a potential explanation for this result the authors cite the necessity of price level adjustment in the absence of currency devaluation within the monetary union. Gomis-Porqueras and Puzzello (2015) apply the SCM to identify the countries that benefited from EMU membership. In support of the Mundell (1961) argument, they find that nations that joined which had closer synchronised business cycles to the monetary union fared better by gaining more or losing less from membership compared to joiners with more desynchronised business cycles.

This paper aims to shed further light on the economic costs and benefits of EMU membership from the perspective a non-member, Sweden. The study contributes to the literature on the implications of monetary union membership in a number of ways. The focus on Sweden is particularly interesting presently, given the country's stance as the largest EU economy outside of the monetary union and the relative lack of material constraints preventing accession, as well as the level of economic advancement of this non-member. We focus on labour productivity, measured as GDP per hour per worker, rather than the level of GDP, as productivity represents a more meaningful metric of economic development for a country that is already economically advanced, as also many other non-members. We further differentiate the analysis by examining the components of expenditure GDP separately, to allow for a more nuanced picture of EMU membership effects beyond productivity, which has not been studied in previous literature. The application of the innovative synthetic control method presents a further contribution to the literature assessing the implications of currency union membership, as it is incorporating dynamic treatment effects and an extensive post-treatment period until 2015, thus including the run-up, peak, and recovery from the recent crisis. This allows for an assessment of the implications of currency union membership robust to business cycle fluctuations.

\section{Data and Methodology}

To answer the question of whether Sweden would have experienced net costs or benefits associated with EMU membership, an appropriate counterfactual analysis is required. A recent innovative methodology, the synthetic control method (SCM), allows for the comparison of an outcome of a unit that undergoes a treatment (or implements a policy) to a synthetic control unit that does not undergo treatment. ${ }^{3}$ The synthetic control unit is formed as a weighted average of untreated comparison units where the weights are chosen such that the resulting combination best resembles values of predictors of the outcome variable for the treated unit prior to the treatment. Three components are specified by the researcher: a treatment and a

\footnotetext{
${ }^{3}$ This methodology was first introduced in Abadie and Gardeazabal (2003) and developed further with inference testing and additional discussion in Abadie et al. (Abadie et al. 2010, Abadie et al. 2015).
} 
treatment period, in this case Sweden not joining the EMU in 1999; a donor pool of comparison units from which the synthetic control is created, here the eleven original Euro Area countries; and outcome predictor variables to link the comparison units to the treated unit, namely variables predicting labour productivity and the components of expenditure GDP. ${ }^{4}$ Ultimately, one observes how the unit of interest is affected by the treatment and aims to compare this to its unobserved, hypothetical development without treatment.

The synthetic control is formed such that the linear combination of donor pool units mimics the pre-treatment values of the treated unit Sweden. Generally, the longer the pre-treatment period, the better fit may be found in terms of minimising the deviation of the synthetic control from the actual series. It follows intuitively that only control units that are similar in both observed and unobserved characteristics can match the treated unit over longer periods of time. Consequently, if it can be established that the synthetic control follows the actual values closely over a longer pre-treatment period, then a deviation in the post-treatment period can be interpreted as being caused by the treatment itself (Abadie et al. 2010). Data for Sweden and the eleven initial EMU members are available yearly over the time period 1980-2015. With the start of treatment in 1999, there are ample years of pre-treatment data and over a decade of post-treatment in which to observe any deviation of synthetic Sweden in the EMU to actual Sweden not in the EMU.

Linking covariates should predict the outcome variables without being affected by the treatment. The literature on the growth drivers and predictors of GDP components is immense. Therefore, in line with the synthetic counterfactual analyses of Abadie and Gardeazabal (2003), Billmeier and Nannicini (2013), as well as Campos et al. (2013), the primary covariates chosen follow growth predictors of Barro and Sala-i-Martin (1995). In addition, a few other variables suggested by the literature for the various components are included, such as demographic measures of population shares above 65 and below 14, as well as the real exchange rate. ${ }^{5}$ Data has been collected primarily from the World Bank World Development Indicators database.

In forming the counterfactual, the optimisation aim is to minimise the distance between the synthetic control and the treated unit, as measured by the root mean squared prediction error (RMSPE). However, the RMSPE is a function of the predefined predictor covariates used in the construction of synthetic Sweden. An issue that emerges is the identification of the set of covariates that minimises the RMSPE. This can in principle deviate from the set including all covariates. Therefore, to obtain the best possible fit an iterative algorithm was applied to compute the RMSPE for each possible set of covariates. The optimal set of covariates is defined to be the set which yields the

\footnotetext{
${ }^{4}$ The original eleven members of EMU from 1999 are Austria, Belgium, Finland, France, Germany, Ireland, Italy, Luxembourg, Netherlands, Spain, and Portugal. Germany was excluded from the donor pool for the labour productivity analysis due to limited comprehensive data.

${ }^{5}$ See for example Aydun et al. (2004) for a discussion of drivers of exports and imports, Shelton (2007) for government expenditure, Gidehag et al. (2001) for investment, Berg and Bergstrom (1995) for consumption, also with discussions of specific drivers for Sweden.
} 
lowest RMSPE and includes at least three covariates. This iterative process is to the best of the author's knowledge a novelty in the literature applying the SCM. The RMSPE fell for all outcome variables, with gains of around $20 \%$ reductions in prediction error (see Table 1). Table 2 demonstrates the different covariate specifications for labour productivity and each component of GDP. All subsequent analyses were conducted using both the full set of covariates, denoted baseline specification and available upon request, as well as the lowest RMSPE set of covariates, denoted best fit specification, presented here.

Now follows a more technical description of the methodology. Suppose there are $J$ control units constituting the donor pool, indexed by $\mathrm{j}$, and one unit undergoing treatment, for a total of $\mathrm{J}+1$ units. $^{6}$ In this paper, Sweden is unit 1 , the country of interest, and there are 11 control units represented by the initial EMU members. Assume a balanced panel can be formed of these $\mathrm{J}+1$ units over some $\mathrm{T}$ time periods, indexed by t. Further assume there is some positive number of pre-treatment periods and some positive number of post-treatment periods, where the start of the treatment period is denoted by $T_{0}$ such that $1<T_{0}<T$. Assume the treatment has no effect prior to $T_{0}$ and has uninterrupted effect when $t \in\left[T_{0}, T\right]$. Let this full post-treatment period be denoted by $T_{1}$. The objective is to compare the treated unit to the synthetic untreated unit when $t \in\left[T_{0}, T\right]$, based on a fit of the synthetic control to the actual treated unit in the pre-treatment period, $t \in\left[1, T_{0}\right]$. In the present paper, pre-treatment starts from 1980 and treatment is set to start in 1999, when the EMU was officially instated. The posttreatment period is comprised of data 1999-2015.

Let $X_{1}=\left[\begin{array}{c}X_{11} \\ \vdots \\ X_{1 k}\end{array}\right]$ be a vector of pre-treatment values of the $\mathrm{K}$ covariates, growth predictors, for unit 1 being exposed to treatment, that is, the pre-treatment values for Sweden.

$$
\text { Let } X_{0}=\left[\begin{array}{ccc}
X_{11} & \ldots & X_{1 j} \\
\vdots & \ddots & \vdots \\
X_{k 1} & \ldots & X_{k j}
\end{array}\right] \text { be a K x J matrix of the pre-treatment values for the } \mathrm{K}
$$

covariates for the $\mathrm{J}$ control units, i.e. the pre-treatment values for the 11 Eurozone countries, forming a $\mathrm{K} \times 11$ matrix.

$$
\text { Let } W=\left[\begin{array}{c}
w_{2} \\
\vdots \\
w_{J+1}
\end{array}\right] \text { be a vector of weights for the control units forming the synthetic }
$$

control such that the following conditions hold;

$$
w_{i} \geq 0 \forall i \text { and } \sum_{i=2}^{J+1} w_{i}=1
$$

Thus, selecting a particular $\mathrm{W}$ is equivalent to selecting a particular synthetic control. As suggested previously, the synthetic control is formed by creating a linear combination of the donor pool units such that it mimics the pre-treatment values of the unit of interest. That is, the synthetic control for Sweden is comprised of a weighted average of the eleven EMU countries in the donor pool such that the combination provides the closest pre-treatment match to Sweden, where closeness is measured by vector $X_{1}-$ $X_{0} W$. Although linearity is a characteristic of the methodology, Abadie et al. (2015)

\footnotetext{
${ }^{6}$ For studies where there are more than one unit undergoing treatment the method may be applied to each unit separately or to all units affected by treatment aggregately (Abadie et al. 2010).
} 
show that also an alternative regression based approach to treatment effects evaluation implicitly relies on a linear combination of the untreated units where the coefficients sum to one.

Consider covariate $a$, one of the $\mathrm{K}$ covariates, such that $X_{1 a}$ is the pre-treatment value of $a$ for unit 1 and $X_{0 a}=\left[\begin{array}{lll}X_{01} & \ldots & X_{0 j}\end{array}\right]$ is a vector of the pre-treatment values for the $\mathrm{J}$ control units. Then, the weighting matrix $\mathrm{W}$ is chosen to minimise the following expression

$$
\sum_{a=1}^{k} v_{a}\left(X_{1 a}-X_{0 a} W\right)^{2}
$$

Where $v_{a}$ is a measure of the relative importance for covariate $a$ in predicting the outcome of interest. For example, in the current paper, GDP per capita and inflation are predictors of consumption. Now, assume GDP per capita is a better predictor of consumption in Sweden than inflation, then it is important that the synthetic control matches the GDP per capita of Sweden closer than its inflation history. Let $\mathrm{V}$ be a square matrix of these relative weights chosen among positive semidefinite and diagonal matrices such that the mean squared error of the synthetic control estimator is minimised over the pre-treatment period. It is not necessary for the time series of the variables considered to be stationary to be able to form the weighting matrix or to determine the relative importance of the predictor variables. Rather, in constructing the weighting matrix it is vital to determine which variables are better predictors of the outcome variable for the treated unit and that these be assigned greater weights, for which stationarity is not a requirement (Abadie et al. 2015).

The synthetic control estimator compares the post-treatment outcome of the treated unit to that of the untreated synthetic control. Let $Y_{1}=\left[\begin{array}{c}Y_{1 T_{0}} \\ \vdots \\ Y_{1 T}\end{array}\right]$ be a vector of posttreatment values of the outcome for the unit of interest, that is, post-treatment values for each of the GDP components of Sweden. Let $Y_{0}=\left[\begin{array}{ccc}Y_{0 T_{0}} & \ldots & Y_{j T_{0}} \\ \vdots & \ddots & \vdots \\ Y_{0 T} & \ldots & Y_{j T}\end{array}\right]$ be a $T_{1} x J$ matrix of post-treatment values of the outcome for the J control units, thus, six matrices of post-treatment values for GDP and each of the components of GDP for the 11 units in the donor pool. In general, let $Y_{j t}$ represent the outcome of unit $\mathrm{j}$ at time t. The synthetic control estimator, reflecting the difference between the treated and the synthetic untreated unit, is given by;

$$
Y_{1 t}-\sum_{j=2}^{J+1} w_{j}^{*} Y_{j t}, t \geq T_{0}
$$

The method can be readily executed using the software scripts developed and made available by Abade, Diamond, and Hainmueller. ${ }^{7}$

\footnotetext{
${ }^{7}$ See http://www.stanford.edu/ jhain for more information and download support.
} 


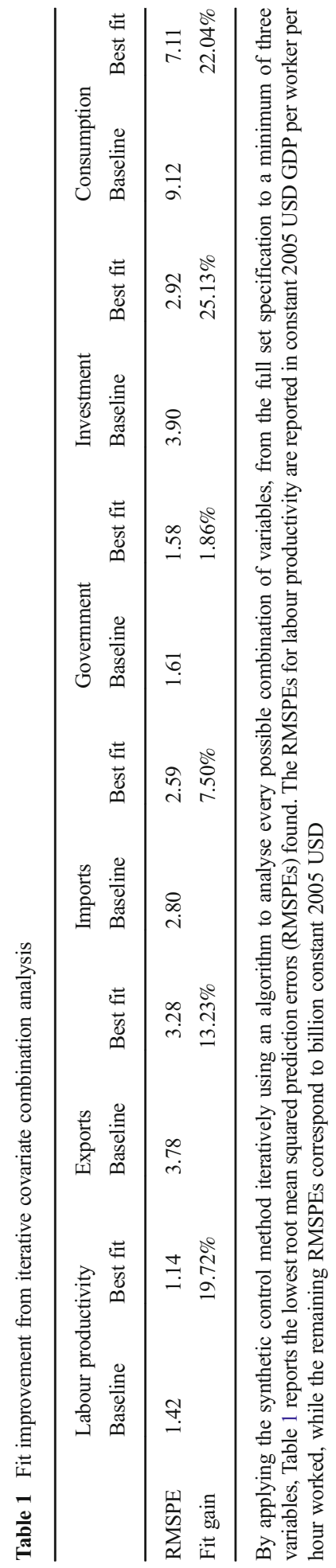




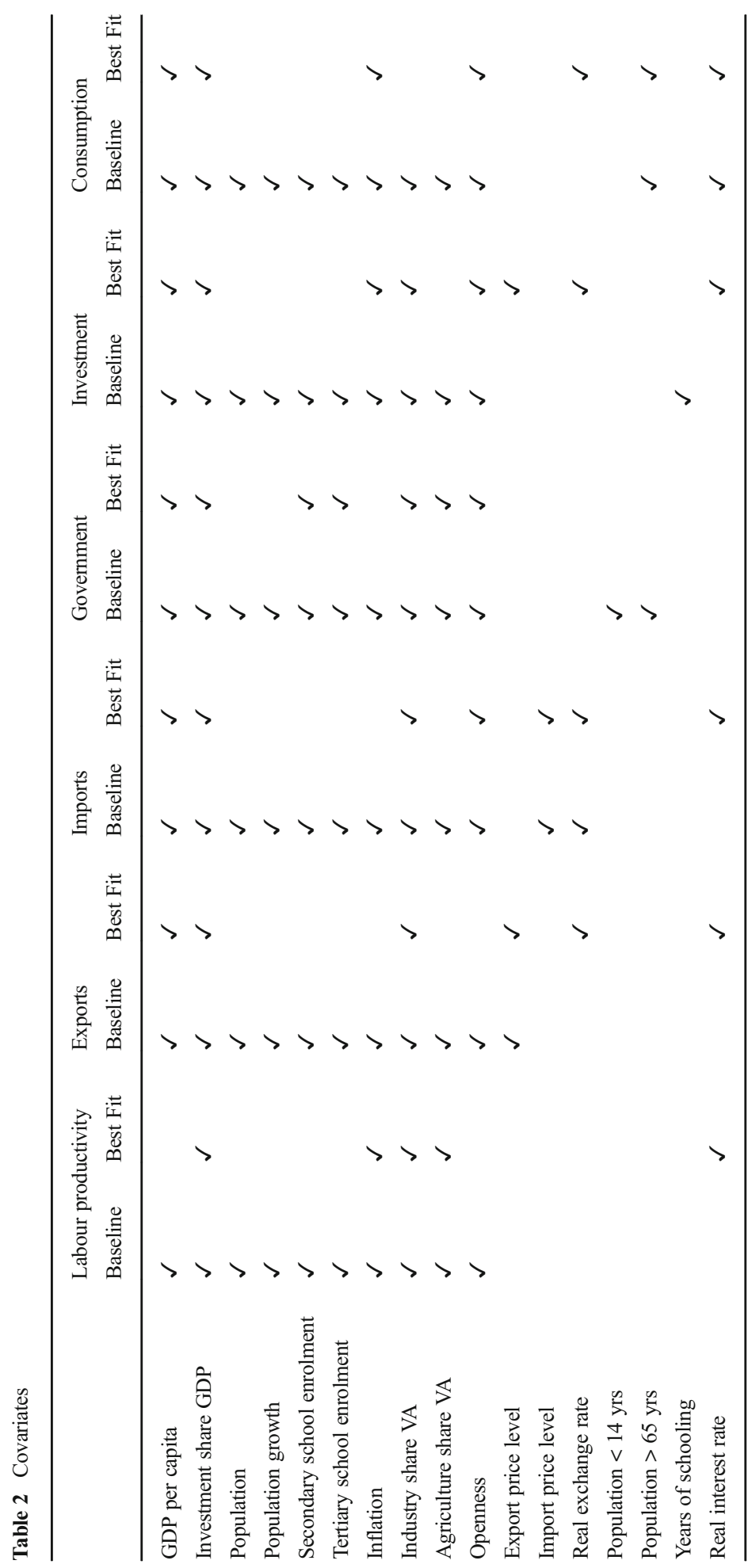




\section{Results}

Results from the synthetic control method estimation using the combination of variables that yield the lowest RMSPE are reported in the first set of figures. The solid line represents actual Sweden, the dashed line synthetic Sweden, with the dashed vertical line at 1999, representing treatment - the commencement of the EMU. Using these figures, the aim is to discern whether there is a deviation of synthetic to actual Sweden from 1999 onward. Accompanying secondary figures and display the percentage difference between the two series for each year in the post-treatment period, illustrating the magnitude of the gap and its persistence over time.

Figure 2 displays the counterfactual analysis for labour productivity. Actual Sweden and its synthetic control are moving congruently together in the pre-treatment period, reflecting a close match of the synthetic control to the actual data series, with a clear and widening gap from 1999 onward, most prominent from 2002. The graph suggests labour productivity would have had a substantially flatter positive trend if Sweden had joined the EMU. Furthermore, the difference between the two units is growing over time, suggesting a persistent and increasing benefit in terms of greater productivity enhancement from opting to remain outside the common currency area. The percentage difference between observed and counterfactual productivity is plotted in Fig. 3. Swedish labour productivity peaks in excess of its synthetic control in 2006, where a $10 \%$ deviation is recorded. The gap subsequently reduces slightly, but remains steady around $8 \%$ throughout the remainder of the post-treatment period. Such persistent subdued productivity development would imply non-negligible cumulative losses in potential economic output. From the perspective of an advanced economy like Sweden it therefore appears that there may be an economically significant disadvantage in joining the EMU.

The synthetic control unit is composed of 36\% Netherlands, 32\% Portugal, $26 \%$ Germany, and $6 \%$ Finland. The importance of Netherlands as a constituent of the control unit in mimicking Sweden is substantial, and follows from similarities in economic developments and size of the two nations compared to other donor pool countries. The inclusion of Portugal in the synthetic control stems from the relative similarity to Sweden in terms of inflation history and industry share of value added which feature as predictor variables. Both Germany and Netherlands have had generally improving labour productivity in line with that of Sweden.

With regard to exports, actual and synthetic Sweden move harmoniously together as one line throughout the full pre-treatment period as well as past the 1999 treatment start (see Figure 4). This prolonged co-movement during the first years of the EMU suggests Sweden would have recorded roughly the same amounts of exports as a member of the currency bloc than as a non-member. However, around 2003 a deviation between the two series emerges with the gap increasing over the post-treatment period, indicating that actual Swedish exports steadily exceeded the amounts that would have been recorded had Sweden opted to join the currency union. The magnitude of this difference is observable in Fig. 5, which plots the percentage difference in each year of the post-treatment period. Actual exports exceed the counterfactual amounts by around $10 \%$ each year since 2010 , with the greatest deviation implied in 2015 at a magnitude of 15\%. The widening gap would suggest a permanent rather than temporary effect of EMU membership. Greater exports have a ceteris paribus positive effect on the trade balance, contributing to greater overall GDP. This result further suggests that Sweden did not suffer trade discrimination and decreased exporting 
opportunities due to currency union non-membership as suggested by for example Micco et al. (2003).

Using the best fit specification, the RMSPE fell by around 20\% compared to the baseline specification. Using this former specification of predictor variables, the synthetic control unit includes $82 \%$ Finland, 15\% France, and 3\% Italy. Due to geographic and demographic similarities it follows that the synthetic control for exports includes such a prominent share composed of Finland. The primary export goods of both Sweden and Finland include for example chemicals, machinery, and timber, in addition to the two countries having exporting partners in common, for example Germany and the United States. ${ }^{8}$ As such, the two countries are exposed to similar trends and shocks, while also sharing similar characteristics in underlying predictor variable time series.

Further net benefit to the trade balance is indicated by the results for imports as the synthetic counterfactual series is predicted to exceed the actual series over the posttreatment period, i.e. counterfactual Swedish imports under the treatment of EMU membership exceed actual Swedish imports. From a chronological standpoint, Fig. 6 shows that the synthetic control unit follows actual Swedish data closely throughout the pre-treatment period as well as into the early years of the EMU. However, by 2001 a gap appears which persists with a relatively large and persistent magnitude around $10 \%$ in the years leading up to the global financial crisis. Nevertheless, in more recent years, the deviation appears to be reducing slightly, suggesting that the effect of EMU membership on imports may be temporary (see Fig. 7). The synthetic control unit is composed of $82 \%$ Finland, and $18 \%$ France, again a reflection of the economic similarities between Sweden and Finland, especially in terms of trade patterns.

The result of the synthetic counterfactual analysis of government expenditure is displayed in Fig. 8. As might be expected a priori, actual government spending exceeds that of the synthetic control during the 1991 recession as this idiosyncratic shock cannot be fully mimicked by the control unit. The analysis for government expenditure differs interestingly from the counterfactual assessments of the remaining variables as it is the only case where an initially increasing gap between the synthetic and the actual series is subsequently reversed and reduces toward the end of the post-treatment period. Such diminishing deviation may suggest that the effect of EMU membership on public spending is temporary rather than permanent. The deviation between the synthetic and the actual units that emerges during the post-treatment period suggests that Swedish government expenditure would have been greater as a member of EMU than as a non-member. Since the introduction of the euro, synthetic expenditure grows in excess of actual government spending with a widening gap that reaches a peak of $10 \%$ in 2008, and subsequently reduces gradually over the remainder of the post-treatment period (see Fig. 9). This suggests a substantially increased need for expanded government expenditure during the crisis within the currency union than without it. Notwithstanding the subsequently diminishing gap, observing differences to the magnitude of $8-10 \%$ on a yearly basis over the span of around a decade would imply a substantial cumulative increase in expenditure. Such increased public outlay would have required

\footnotetext{
${ }^{8}$ See trade reports produced by the respective statistics agencies: Finland: http://www.stat. fi/tup/suoluk/suoluk_kotimaankauppa_en.html and Sweden: http://www.scb.se/en/finding-statistics/statisticsby-subject-area/trade-in-goods-and-services/foreign-trade/foreign-trade-exports-and-imports-of-goods/, retrieved May 2, 2017.
} 
financing either through fiscal measures (with potential political impact) or increased accumulation of public debt. In the absence of effective fiscal disciplinary tools and overall mechanisms promoting the convergence of economic developments, external imbalances emerge (De Grauwe and Ji 2015).

The synthetic control unit for government expenditure is composed of 57\% Austria, 32\% Belgium, $10 \%$ Italy, and $1 \%$ Germany. As the number of elements in the covariate set falls to achieve the best fit specification, Austria enters as a prominent constituent of the control unit. This is due to similarities with the data recorded for Sweden, where for example Austria, which shares demographic characteristics and educational pervasion with Sweden enters the synthetic control, while the more idiosyncratic developments of for example Luxembourgish data lends the country less fitting as a control unit component.

With regard to investment, Fig. 10 illustrates further how closely Finnish economic developments and exposure to business cycle fluctuations may mimic those of Sweden. This becomes evident when considering the composition of the synthetic control unit that is composed almost exclusively of Finland at a share of $89 \%$, while the remaining $11 \%$ corresponds to Italy. As opposed to the previous outcome variables, the difference between the synthetic and the actual series remains immaterial for a comparatively substantial part of the post-treatment period. However, from 2010 onward, Swedish investment, measured as gross fixed capital formation, assumes extraordinarily strong growth, while the synthetic counterfactual series undergoes contraction (see Fig. 11). Indeed, investment in Sweden has generally exceeded both the euro area average and most individual EMU member countries over recent years following the peak of the global financial crisis. ${ }^{9}$

The relationship between the synthetic and the actual series with regard to consumption follows a similar trend to investment (see Fig. 12). There is relatively strong co-movement during the pre-treatment period as well as for a substantial part of the post-treatment years. Household consumption responds to idiosyncratic business cycle fluctuations, which complicates the formation of a better fitting synthetic control. The 1991 recession and the sluggish recovery are apparent in the actual data series, which cannot be perfectly matched by the synthetic control. Nevertheless, this impact is mitigated by the inclusion of Finland in the synthetic control which undergoes a similar economic downturn in the early 1990s. The synthetic control unit is composed of $84 \%$ Finland, $8 \%$ Luxembourg, 6\% Italy, and 2\% France. Furthermore, in line with investment, a more noteworthy deviation between the two units appears in the aftermath of the global financial crisis eruption. The gap continuously widens from 2012 onward, with a peak in 2015 of actual Sweden exceeding its synthetic counterpart by $10 \%$ (see Fig. 13). This increasing deviation could indicate that the impact of EMU membership on consumption may transition into a more permanent, sustained effect.

To summarise the results of this synthetic control method exercise to determine whether there may be costs or benefits from EMU membership, we find that there appears to be net costs from joining. This finding is uniformly supported by the assessment of labour productivity, defined as GDP per hour per worker, in addition to each of the components of expenditure GDP, where it is found that actual Swedish data exceed the corresponding synthetic counterfactual since the introduction of the euro. The deviations between the actual series and their respective control units generally reach magnitudes close to $10 \%$, indicating non-negligible net benefits from opting to remain outside the common currency








Notes: The figure above illustrates the result of the synthetic control method estimation for labour productivity, where labour productivity is defined as GDP per hour per worker (OECD). See table 2 for the predictor variables and the text for further description of donor pool countries constituting the synthetic control unit.

Fig. 2 Labour productivity synthetic control method estimation

area. The synthetic control unit exceeds the actual unit in the cases of imports and government expenditure. However, greater imports would have a net negative impact on the trade balance and thus GDP, while greater government expenditure would require financing either through fiscal measures or increased public debt accumulation.

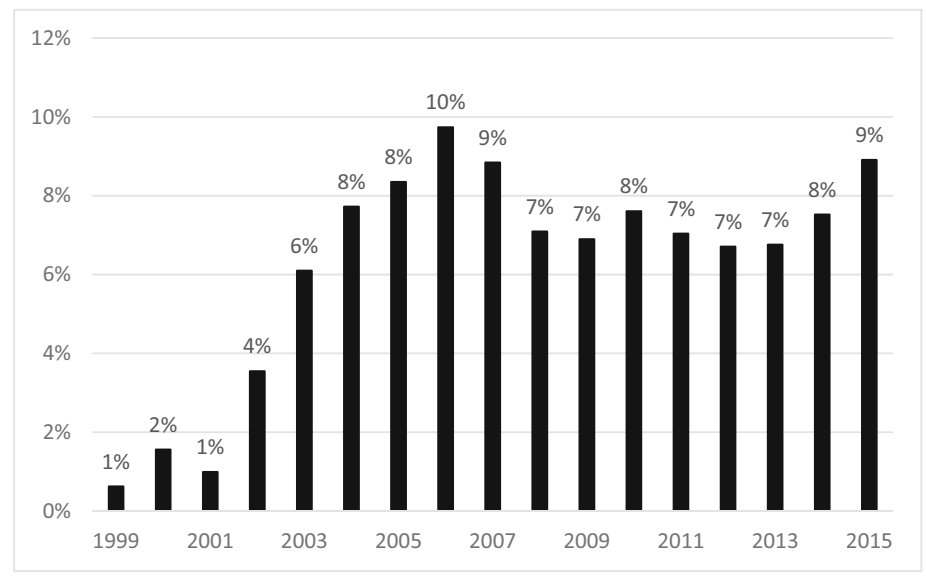

Notes: The figure above plots the percentage difference between actual Sweden and synthetic Sweden in the posttreatment period for the outcome variable indicated in the preceding figure, where a positive (negative) value indicates that the actual series is greater than (smaller than) the synthetic series by that percentage.

Fig. 3 Percentage difference between the actual and the synthetic units in the post-treatment period for labour productivity 


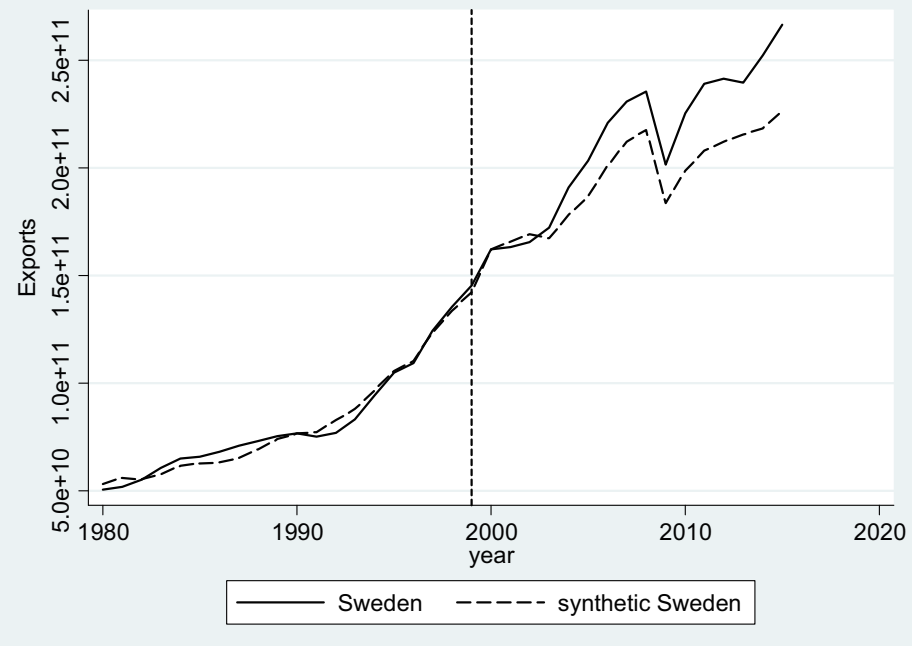

Notes: The figure above illustrates the result of the synthetic control method estimation for exports, measured as billions constant 2005 USD. See table 2 for the predictor variables and the text for further description of donor pool countries constituting the synthetic control unit.

Fig. 4 Exports synthetic control method estimation

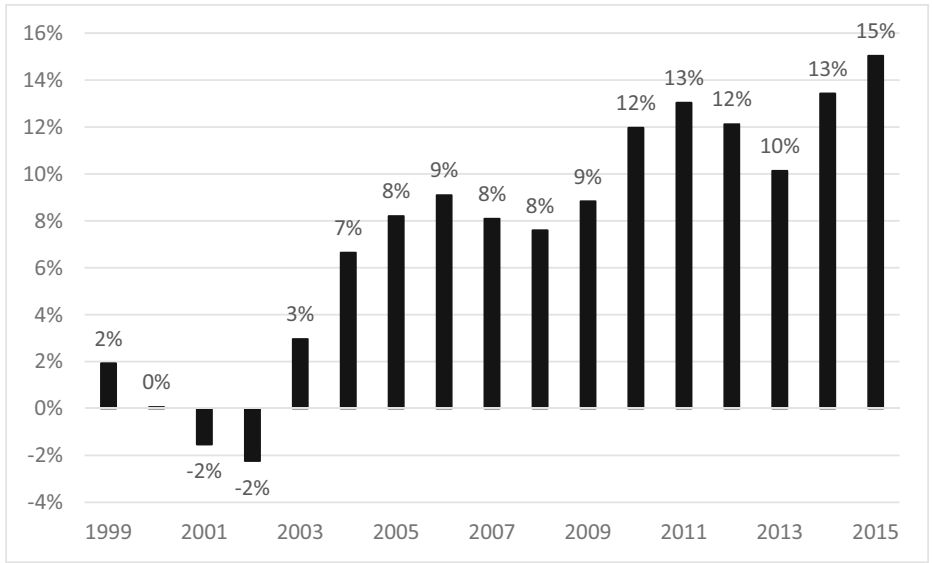

Notes: The figure above plots the percentage difference between actual Sweden and synthetic Sweden in the posttreatment period for the outcome variable indicated in the preceding figure, where a positive (negative) value indicates that the actual series is greater than (smaller than) the synthetic series by that percentage.

Fig. 5 Percentage difference between the actual and the synthetic units in the post-treatment period for exports 




Notes: The figure above illustrates the result of the synthetic control method estimation for imports, measured as billions constant 2005 USD. See table 2 for the predictor variables and the text for further description of donor pool countries constituting the synthetic control unit.

Fig. 6 Imports synthetic control method estimation

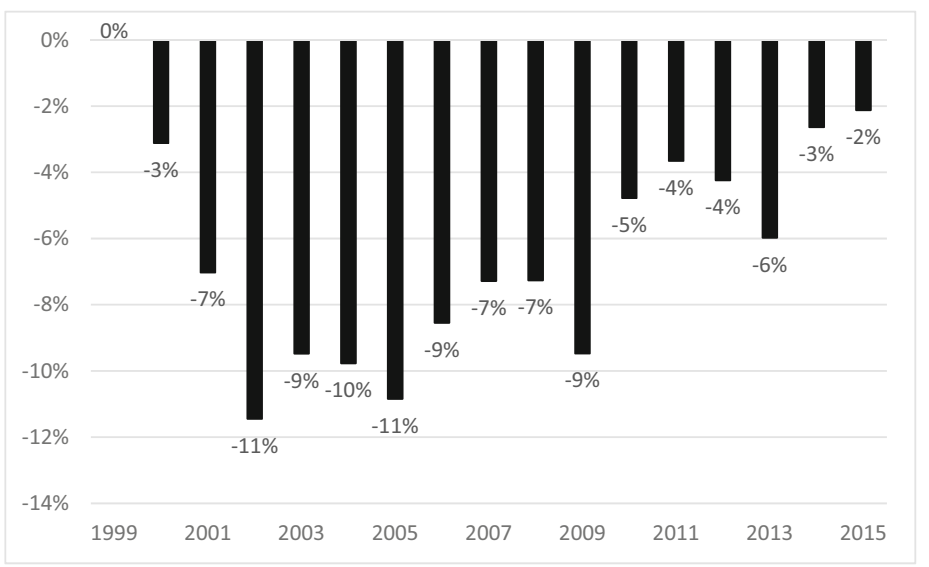

Notes: The figure above plots the percentage difference between actual Sweden and synthetic Sweden in the posttreatment period for the outcome variable indicated in the preceding figure, where a positive (negative) value indicates that the actual series is greater than (smaller than) the synthetic series by that percentage.

Fig. 7 Percentage difference between the actual and the synthetic units in the post-treatment period for imports 


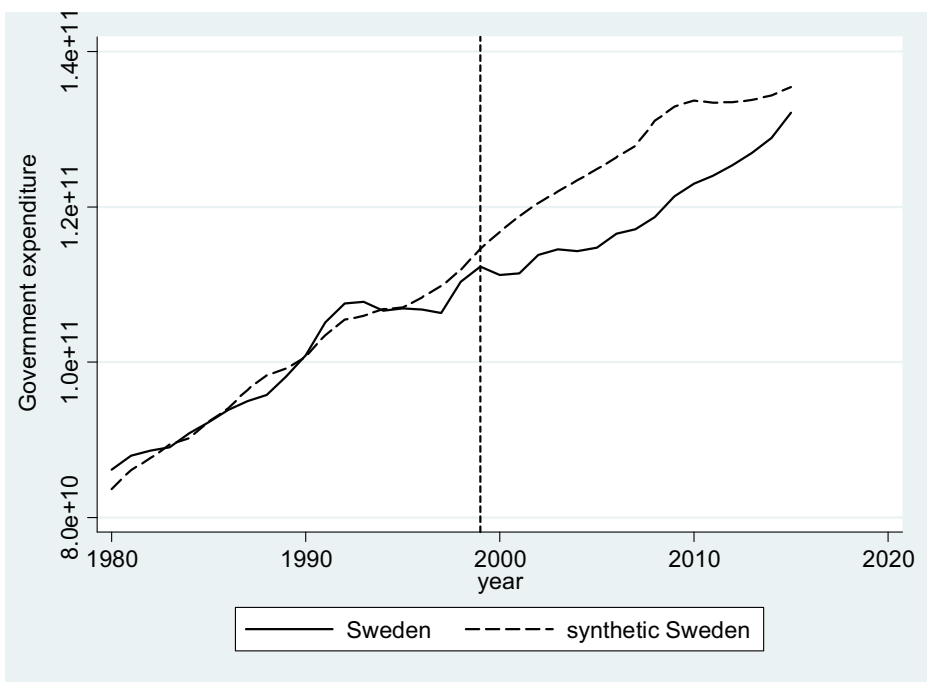

Notes: The figure above illustrates the result of the synthetic control method estimation for government expenditure, measured as billions constant 2005 USD. See table 2 for the predictor variables and the text for further description of donor pool countries constituting the synthetic control unit.

Fig. 8 Government expenditure synthetic control method estimation

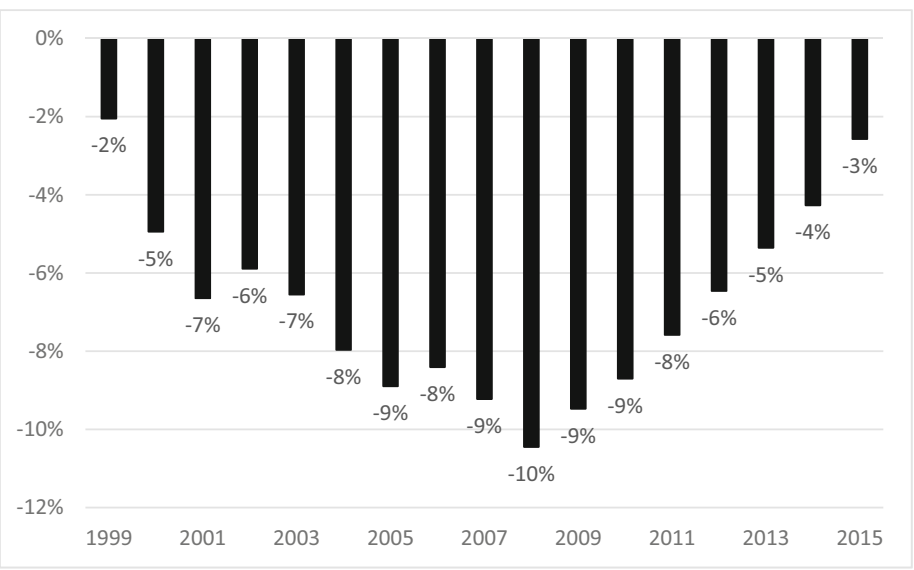

Notes: The figure above plots the percentage difference between actual Sweden and synthetic Sweden in the posttreatment period for the outcome variable indicated in the preceding figure, where a positive (negative) value indicates that the actual series is greater than (smaller than) the synthetic series by that percentage.

Fig. 9 Percentage difference between the actual and the synthetic units in the post-treatment period for government expenditure 


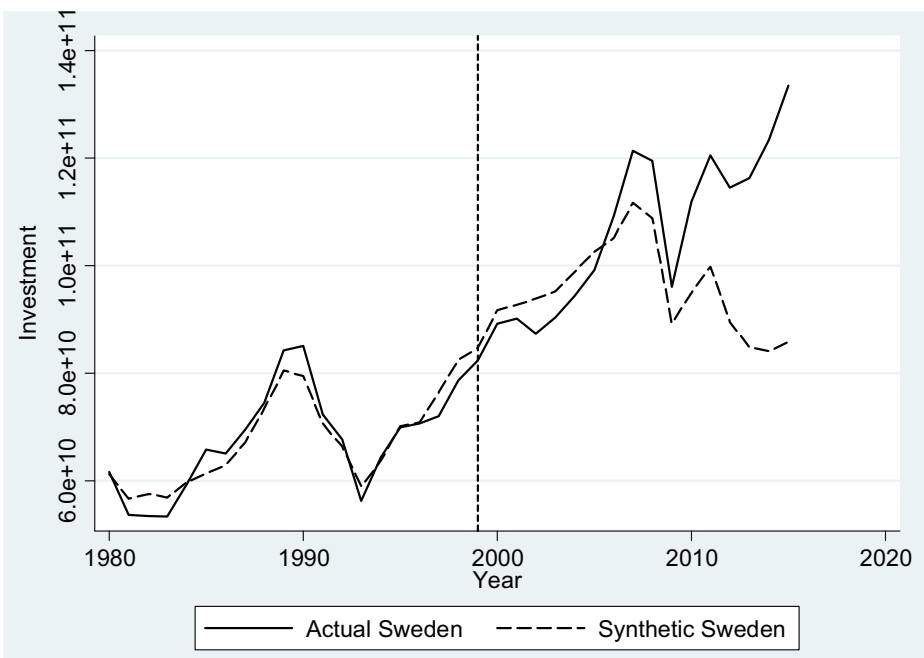

Notes: The figure above illustrates the result of the synthetic control method estimation for investment, where investment is defined as gross fixed capital formation in billions constant 2005 USD. See table 2 for the predictor variables and the text for further description of donor pool countries constituting the synthetic control unit.

Fig. 10 Investment synthetic control method estimation

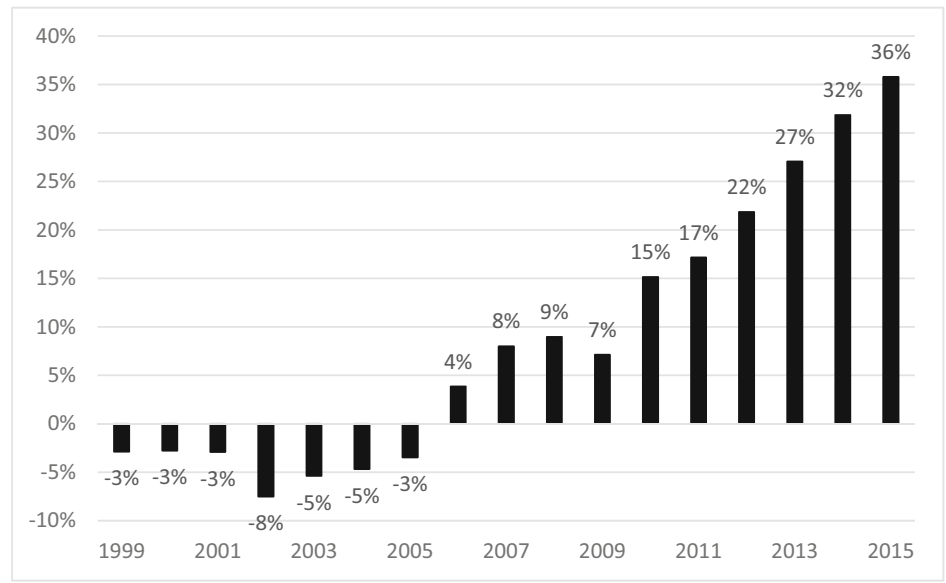

Notes: The figure above plots the percentage difference between actual Sweden and synthetic Sweden in the posttreatment period for the outcome variable indicated in the preceding figure, where a positive (negative) value indicates that the actual series is greater than (smaller than) the synthetic series by that percentage.

Fig. 11 Percentage difference between the actual and the synthetic units in the post-treatment period for investment 


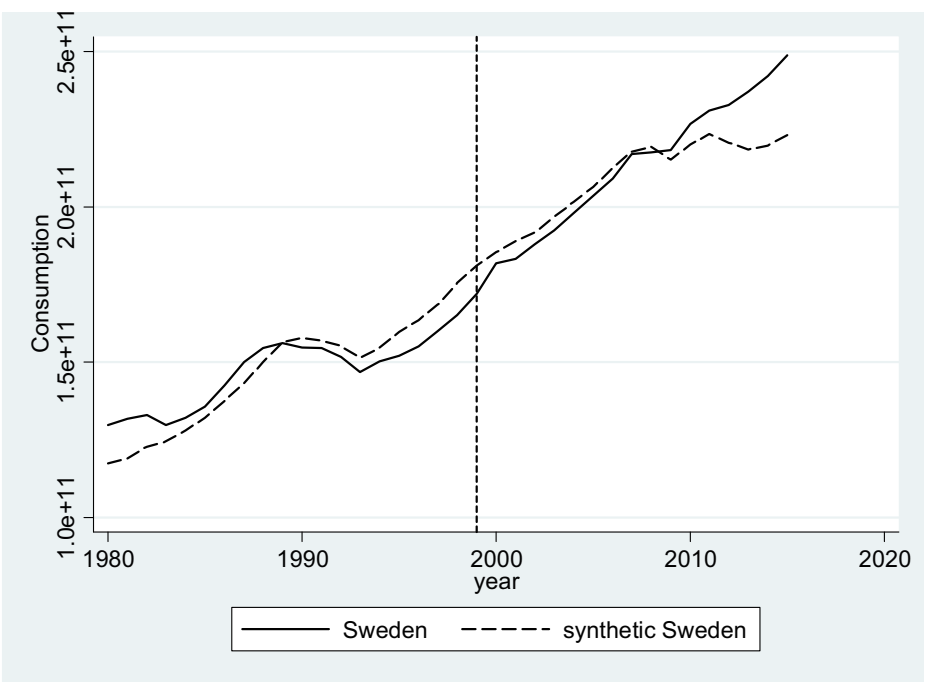

Notes: The figure above illustrates the result of the synthetic control method estimation for consumption, where consumption is defined as final household consumption in billions constant 2005 USD. See table 2 for the predictor variables and the text for further description of donor pool countries constituting the synthetic control unit.

Fig. 12 Consumption synthetic control method estimation

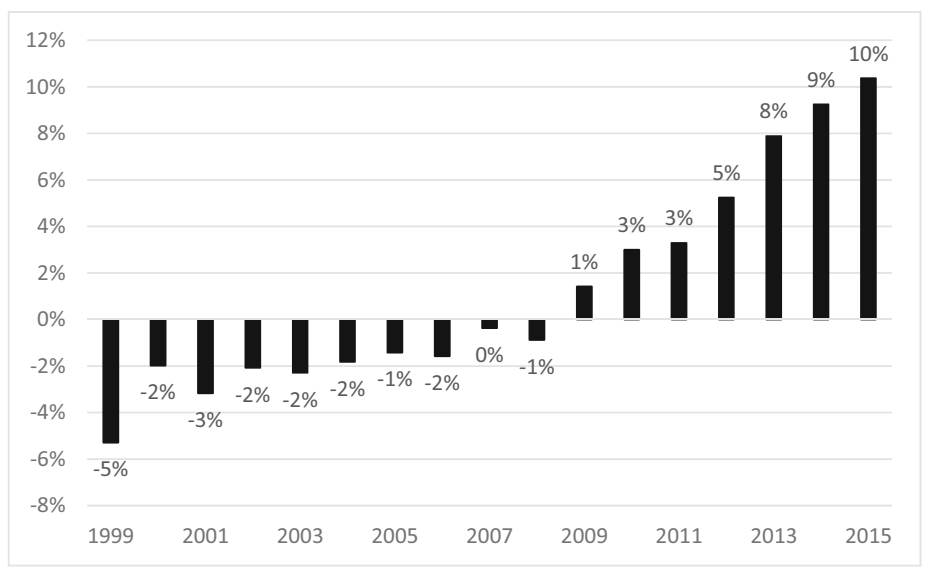

Notes: The figure above plots the percentage difference between actual Sweden and synthetic Sweden in the posttreatment period for the outcome variable indicated in the preceding figure, where a positive (negative) value indicates that the actual series is greater than (smaller than) the synthetic series by that percentage.

Fig. 13 Percentage difference between the actual and the synthetic units in the post-treatment period for consumption 


\section{Inference and Robustness}

The SCM literature speaks primarily of two types of "placebo" testing for inference; in-space and in-time (see for example Abadie et al. 2010, 2015). These tests aim at verifying the method's ability to accurately reflect the effect of the treatment in isolation by assigning treatment to each of the donor pool countries and to an arbitrary point in time prior to actual treatment, respectively. This inference testing is followed by a robustness analysis of using different geographical regions of the euro area as alternative donor pools. Finally results of a difference-in-differences analysis are presented, illustrating the findings from an alternative method of assessing the impact of EMU membership on economic factors.

Placebo in-space testing consists of applying the SCM to all donor countries to determine whether sizable differences may be found between the actual donor country and its corresponding synthetic control. The result of the test is illustrated in a figure plotting the distribution of actual to synthetic differences for all the donor pool countries in addition to Sweden. If the graph for Sweden consistently lies well within the spectrum of donor pool country graphs, there may be reason to believe the original synthetic counterfactual analysis fails to capture a significant treatment effect as it suggests donor pool countries, which did not undergo treatment display greater treatment effects than Sweden which did undergo treatment. Each of the donor pool countries can only be composed of a combination of the other remaining donor pool countries, which, due to the restricted donor pool, renders it statistically challenging to form an appropriate synthetic control for some donor pool countries, e.g. France and Germany. This results in poorly fitting synthetic controls with very high RMSPEs that distort the figures by wrongfully suggesting large treatment effects, while rather being reflections of statistical inadequacy in forming a better control. Indeed, a large RMSPE, and large deviations of the synthetic to the actual control, are not indicative of a large treatment effect if also the RMSPE prior to treatment is large, which holds for many countries in the subsequent analysis. To avoid this erroneous distortive interpretation, such countries are excluded from the graph as suggested by Abadie et al. (2015).

Indeed, in most analyses, Germany, France, and Portugal display such poor fits, to the magnitude of twenty or even up to over fifty times the RMSPE of Sweden, that they were subsequently removed from the figures. Overall, the limited donor pool often is not successful in producing synthetic controls of comparable fits to that of Sweden. Nonetheless, bearing this significant caveat in mind, the plot of the difference between the synthetic and actual Sweden lies, by and large, on the external boundary of the donor country plots. This adds validity to the original results in suggesting that Sweden, which did 
undergo treatment, displays greater treatment effects than the donor pool countries which did not undergo (Fig. 14) treatment.

The intuition for the placebo in-time test is as follows. If the synthetic control has been appropriately constructed, then assigning a hypothetical earlier treatment starting point should still yield a close co-movement of the two series, the actual and the synthetic, until 1999 when the euro was actually introduced. Observing a sizable deviation of the synthetic from the actual series following this artificial treatment start would undermine the results obtained in the original analysis with treatment starting in 1999 as it would suggest the counterfactual is capturing some treatment effect other than that of EMU membership. ${ }^{10}$

Specifically, the placebo in-time tests consist of executing the synthetic counterfactual analysis over the period 1980-1998, with an artificial treatment date set at 1990. There is no evidence of a significant divergence occurring at 1990 in any of the sub- figures presented (see Fig. 15), which adds validity to the original analysis and suggests that the effect recorded by the synthetic control from 1999 onward is caused by EMU. Nevertheless, a slight degree of deviation may be observed in the early 1990s, which follows naturally from the inability of the donor pool countries in mimicking the idiosyncratic shocks experienced by Sweden in this period and should not be interpreted as significant weakening of original results.

As a further robustness check one may apply alternative donor pool specifications of different geographical areas, which allows for the assessment of how results are driven by certain regions and how this affects control unit composition as well as the fit in terms of RMSPE. This study will consider two alternative donor pools denoted as South and North.

Starting with the South donor pool, consisting of France, Italy, Portugal, and Spain in Table 3, one may conclude that the overall greatest prediction errors are produced. The southern countries differ substantially from Sweden in many regards, economically and politically, thus one may have also a priori expectations of a poorer synthetic control fit based on these countries. Spain does not feature in any analysis nor as part of the synthetic control in the original analyses. Portugal on the other hand, given its similarity to Sweden in terms of various aspects of economic data and activity, such as demographics and trade openness, features as a key contributor to the synthetic controls within this regional donor pool, as well as the original counterfactual assessment of labour productivity. Furthermore, France shares some similarities, in particular with respect to trade data and features as a significant contributor to the synthetic control for each of the trade balance components.

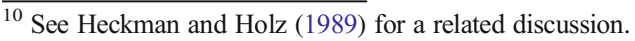


The North donor pool, consisting of Finland, Germany, Ireland, and Netherlands further illustrates the data congruency of Sweden with Finland in terms of economic activity (see Table 4). Finland experienced a similar recession in 1991 and has been subject to comparable shocks and fluctuations as Sweden, in addition to sharing geographic and demographic characteristics influencing economic activity, e.g. trading goods and trading partners. Finland therefore features prominently as a control unit for mimicking Sweden given both full and more geographically focused donor pools.

In Table 4 one can see that Finland corresponds to around $90 \%$ of the synthetic control for the regional assessment of the GDP components. Notwithstanding this, there is a clear benefit in terms of reduced prediction error from utilising an extended donor pool rather than dictating Finland as the sole comparator as one would in direct matching, or a limited donor pool of four or five units as in weighted multiple control unit matching for treatment effects evaluation. Within the setting of SCM estimation, in comparing the RMSPEs produced during the north donor pool exercise compared to the RMSPEs resulting from the full donor pool one may see an improvement in fit of $30 \%$ on average over the six outcome variables (see Table 5). Even greater differences may be observed compared to using Finland as the sole control unit. Here the average reduction of prediction error reaches the magnitudes of almost $70 \%$ on average over the six variables. This additional comparative exercise further illustrates the strength of synthetic control method estimation. Allowing for the inclusion of multiple donors in composing the control unit produces a closer matching counterfactual, thus allowing for more confident treatment effects evaluation. Furthermore, the purely statistically driven procedure involved in constructing the counterfactual unit is free from subjective manipulation by the researcher in terms of designating the control unit composition.

Finally, as a further robustness check of the results, one may view Table 6 displaying the findings from an alternative difference-in-differences analysis. Joining the EMU appears to have a negative impact on all outcome variables considered to an at least weakly significant degree, with the exception of labour productivity where insignificant results are found. The difference-in-differences analysis therefore broadly supports the conclusions of the synthetic control assessment where adopting the euro implies potential economic costs in terms of subdued economic activity. Nevertheless, as opposed to the synthetic control method of estimation which assesses dynamic treatment effects, difference-indifferences compares the average change over time in the outcome variable of the treated unit to the average change in the same variable over time for the untreated unit(s). As such, it fails to capture how the effect of joining the EMU changes over time during the build-up, peak, and on-going recovery from the financial crisis. Notwithstanding such differences, the two analyses appear to be supporting a similar conclusion that joining the EMU entails net economic disadvantages. 

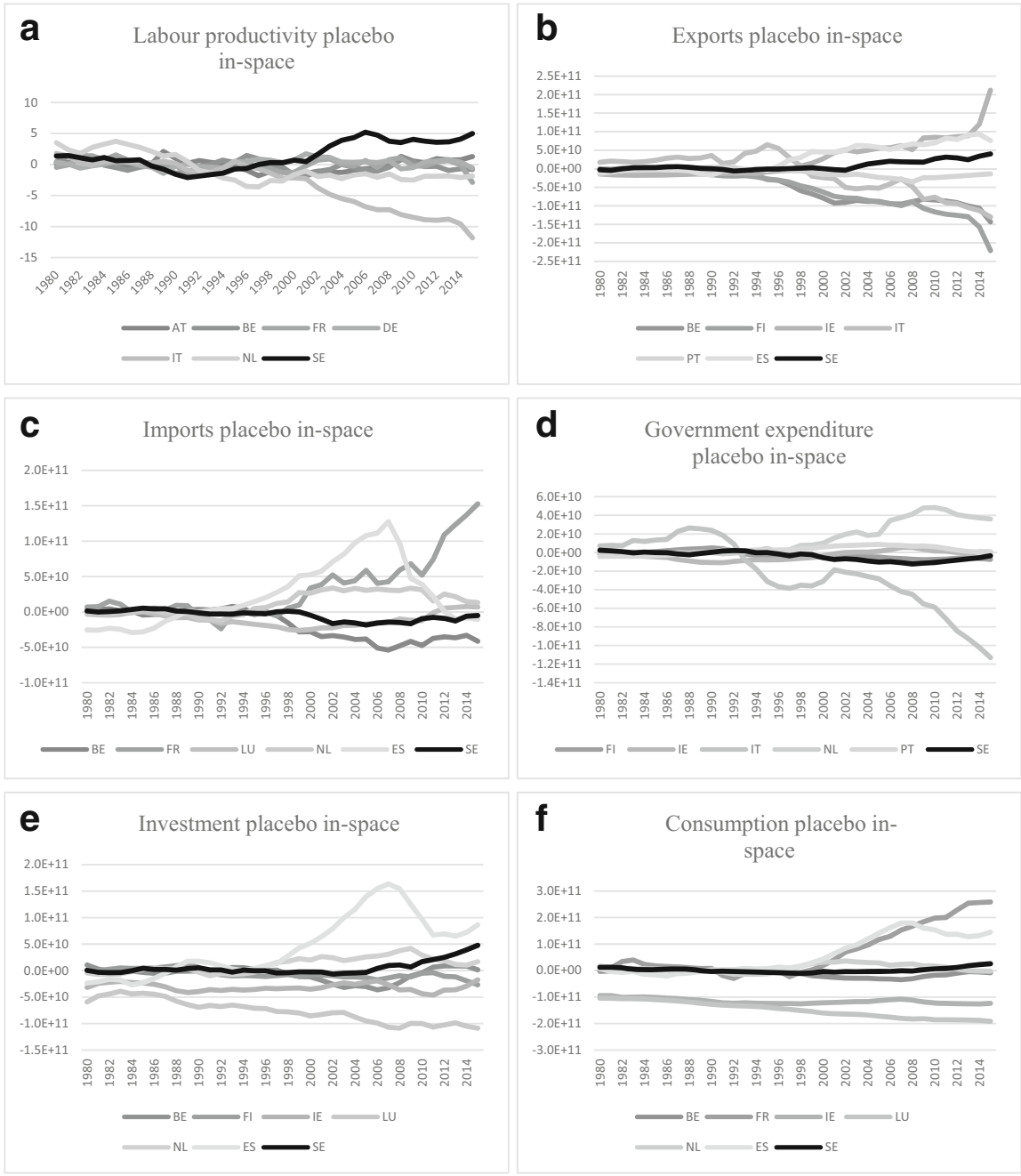

Notes: The above figures display a selection of the distribution of treatment effects from applying the synthetic control method of estimation to each of the donor pool units for each of the outcome variables considered. See text for a description of the outcome variables and their definitions, the associated predictor variables, and interpretation of the results.

Fig. 14 a Labour productivity placebo in-space. b Exports placebo in-space. c Imports placebo in-space. d Government expenditure placebo in-space. e Investment placebo in-space. f Consumption placebo in-space 

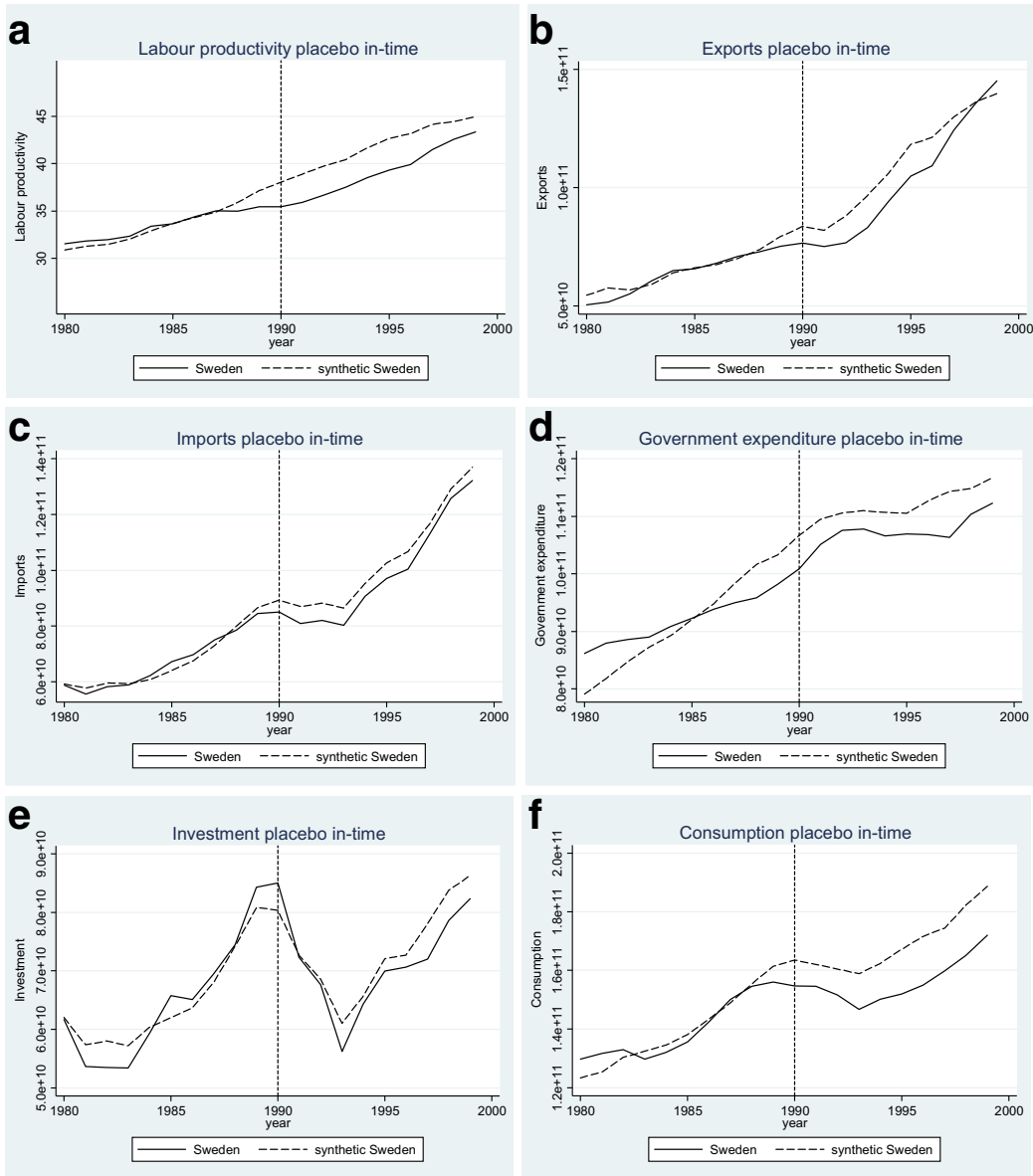

Notes: The above figures display the results from applying the synthetic control method of estimation to each of the outcome variables setting an arbitrary treatment starting point in 1999. See text for a description of the outcome variables and their definitions, the associated predictor variables, and interpretation of the results.

Fig. 15 a Labour productivity placebo in-time. b Exports placebo in-time. c Imports placebo in-time. d Government placebo in-time. e Investment placebo in-time. f Consumption placebo in-time

Table 3 South donor pool

\begin{tabular}{lcccccc}
\hline & Labour productivity & Exports & Imports & Government & Investment & Consumption \\
\hline RMSPE & 1.8 & 5.55 & 8.17 & 7.33 & 10.0 & 13.7 \\
France & 6.8 & 19.3 & 18.1 & 16.7 & 0 & 0 \\
Italy & 70.7 & 0 & 0 & 0 & 11.9 & 5.3 \\
Portugal & 22.6 & 80.7 & 81.9 & 83.3 & 88.1 & 94.7 \\
Spain & 0 & 0 & 0 & 0 & 0 & 0 \\
\hline
\end{tabular}

Table 3 displays the percentage composition of the synthetic control for labour productivity and the components of GDP as described in the text, using a regional donor pool specification of France, Italy, Portugal, and Spain, for the best fit specification of variables (see text and Table 2 for further details). Labour productivity is measured as GDP per hour per worker in terms of constant 2005 USD, while the remaining outcome variables are measured in billion constant 2005 USD. 
Table 4 North donor pool

\begin{tabular}{lcccccc}
\hline & Labour productivity & Exports & Imports & Government & Investment & Consumption \\
\hline RMSPE & 2.37 & 3.74 & 3.84 & 2.64 & 3.73 & 8.27 \\
Finland & 33.2 & 81.6 & 89.1 & 87.3 & 94.0 & 88.6 \\
Germany & 54.1 & 5.5 & 10.9 & 12.7 & 6.0 & 3.9 \\
Ireland & 9.9 & 0 & 0 & 0 & 0 & 0 \\
Netherlands & 2.8 & 12.9 & 0 & 0 & 0 & 7.6 \\
\hline
\end{tabular}

Table 4 displays the percentage composition of the synthetic control for labour productivity and the components of GDP as described in the text, using a regional donor pool specification of Finland, Germany, Ireland, and Netherlands, for the best fit specification of variables (see text and Table 2 for further details). Labour productivity is measured as GDP per hour per worker in terms of constant 2005 USD, while the remaining outcome variables are measured in billion constant 2005 USD.

Table 5 Comparison of prediction errors from limited donor pools

\begin{tabular}{lllllll}
\hline & $\begin{array}{l}\text { Labour } \\
\text { productivity }\end{array}$ & Exports & Imports & Government & Investment & Consumption \\
\hline North donor pool & 2.37 & 3.74 & 3.84 & 2.64 & 3.73 & 8.27 \\
Full donor pool & 1.139 & 3.28 & 2.59 & 1.58 & 2.92 & 7.11 \\
$\begin{array}{l}\text { Finland as control } \\
\text { RMSPE reduction } \\
\text { to north }\end{array}$ & 5.25 & 4.92 & 4.71 & 5.62 & 31.5 & 67.8 \\
$\begin{array}{l}\text { RMSPE reduction } \\
\text { to Finland }\end{array}$ & $-78 \%$ & $-12 \%$ & $-33 \%$ & $-40 \%$ & $-22 \%$ & $-14 \%$ \\
\hline
\end{tabular}

Table 6 Difference-in-Differences results

\begin{tabular}{lllllll}
\hline & $\begin{array}{l}\text { Labour } \\
\text { productivity }\end{array}$ & Exports & Imports & $\begin{array}{l}\text { Government } \\
\text { expenditure }\end{array}$ & Investment & Consumption \\
\hline $\begin{array}{l}\text { D-i-D } \\
\text { coefficient }\end{array}$ & 0.96 & $-0.11^{* * *}$ & $-0.12 * * *$ & $-0.04 *$ & -0.03 & $-0.10^{*}$ \\
$\begin{array}{l}p \text {-value } \\
\text { R-squared }\end{array}$ & 0.558 & 0.000 & 0.000 & 0.054 & 0.115 & 0.081 \\
Observations & 0.29 & 0.18 & 0.19 & 0.04 & 0.05 & 0.05 \\
\hline
\end{tabular}

* significant at $10 \% ; * *$ significant at $5 \% ; * * *$ significant at $1 \%$ 


\section{Conclusion}

This paper has shed light on the economic costs and benefits of the important irreversible policy decision to join the European Monetary Union faced by European Union members outside the euro. Exchange rate stability, enhanced trading opportunities, lower interest rates, and greater output are some of the potential benefits associated with accession. Potential costs include repercussions due to loss of independent monetary and budgetary policies, as well as the inability to enhance competitiveness through currency devaluation. Although Sweden would become subject to the centrally set guiding interest rates determined by the European Central Bank, it would also alter the composition of the forces determining the trajectory of this policy instrument. Altering the course of European monetary policy would impact both economic developments in Sweden and in the present members of the monetary union. Swedish EMU membership would affect both the economic factors, i.e. the economic conditions considered in setting the overall optimal level of interest rates, and non-economic factors that guide monetary policy decisions, such as expectations of economic agents and external pressures on the ECB, e.g. popular support (Maier and Hendrikx 2002). The implications of Swedish EMU membership thereby affects both national and international developments as well as policy decisions.

We apply the innovative synthetic counterfactual method of estimation to assess the potential impact of currency union membership. We compare actual Sweden, which did not join the monetary union, to a hypothetic Sweden, composed of a statistically derived weighted average of the original euro area countries, which did join the union. A novelty in the utilisation of this estimation method is the application of an iterative algorithm to assess each possible combination of predictor variables of productivity and the GDP components to obtain the closest fit of the synthetic series to the actual series. This process succeeds in reducing the prediction error to a degree of around $20 \%$ for most outcome variables.

The findings suggest that Sweden would have borne non-negligible costs from EMU membership, exemplified by around 10\% lower labour productivity, exports, investment, and consumption on a yearly basis since the introduction of the euro, leading to even greater cumulative losses in potential economic output. Simultaneously, imports and government expenditure are predicted to have been around $8 \%$ higher each year had Sweden joined the monetary union, where higher imports have a net negative impact on the trade balance and expanded government expenditure requires support primarily from either fiscal measures or increased public debt. This result conforms to previous literature where Mazumder and Pahl (2013) find that the United Kingdom would have had higher unemployment and lower output had it joined the EMU in 1999, as well as Manasse et al. (2014) and Faina et al. (2012) who suggest that Italy and Spain would have fared better outside of the EMU in terms of augmented labour productivity, respectively.

The estimated costs associated with EMU membership may be due to shortcomings, or "design flaws" of this union, e.g. the absence of common fiscal policy and effective controls, a single monetary policy applied without mechanisms to promote business cycle convergence among members, and failure to oversee financial stability. However, in light of significant recent reforms and the implementation of policies and institutions such as the Banking Union, the European Stability Mechanism, as well as the Single Supervisory Mechanism and Single Resolution Mechanism, some of these shortcomings have been corrected such that the balance of economic costs and benefits of EMU membership may be 
shifting. It is left for future research to determine whether such measures have proven effective in resolving the shortcomings and support prospective net benefits in joining the EMU.

Acknowledgements I would like to thank Nauro Campos for valuable comments on earlier versions of this paper, Benedetta Bianchi, as well as Ansgar Belke, Daniel Thornton, and other conference participants at the 2016 European Economics and Finance Society and Warsaw International Economics Meeting for helpful comments and suggestions. I also thank two anonymous referees for valuable comments. The views expressed in this paper are the personal views of the author.

Open Access This article is distributed under the terms of the Creative Commons Attribution 4.0 International License (http://creativecommons.org/licenses/by/4.0/), which permits unrestricted use, distribution, and reproduction in any medium, provided you give appropriate credit to the original author(s) and the source, provide a link to the Creative Commons license, and indicate if changes were made.

\section{References}

Abadie A, Gardeazabal J (2003) The economic costs of conflict: a case study of the Basque country. Am Econ Rev 93:113-132

Abadie A, Diamond A, Hainmueller J (2010) Synthetic control methods for comparative case studies: estimating the effect of California's tobacco control program. J Am Stat Assoc 105:493-505

Abadie A, Diamond A, Hainmueller J (2015) Comparative politics and the synthetic control method. Am J Polit Sci 59(2):495-510

Aguiar-Conraria L, Soares MJ (2011) Business cycle synchronization and the Euro: a wavelet analysis. J Macroecon 33(3):477-489

Arghyrou MG, Kontonikas A (2012) The EMU sovereign-debt crisis: fundamentals, expectations and contagion. J Int Financ Mark Inst Money 22(4):658-677

Artis M, Krolzig H-M, Toro J (2004) The European business cycle. Oxf Econ Pap 56:1-44

Aydun, M. F., Ciplak, U., Yucel, M. E. (2004). Export supply and income demand functions for the Turkish economy. The Central Bank of the Republic of Turkey Research Department Working Papers No. 04/09

Barro R, Sala-i-Martin X (1995) Economic growth, 2nd edn. MIT Press, Cambridge

Berg L, Bergström R (1995) Housing and financial wealth, financial deregulation and consumption: the Swedish case. Scand J Econ 421-439

Begg D, Chiappori P-A, Giavazzi F, Mayer C, Neven D, Spaventa L, Vives X, Wyplosz C (1991) The making of monetary union, monitoring European integration No. 2. CEPR, London

Bianchi B (2016) Sovereign risk Premia and the international balance sheet: lessons from the European crisis. Open Econ Rev 1-23

Billmeier A, Nannicini T (2013) Assessing economic liberalisation episodes: a synthetic control approach. Rev Econ Stat 95(3):983-1001

Böwer U, Guillemineau C (2006) Determinants of business cycle synchronisation across euro area countries. European Central Bank Working Paper No. 587

Calmfors L, Flam H, Gottfries N, Jerneck M, Lindahl R, Haaland Matlary J, Rabinowicz E, Vredin A, Nordh Berntsson C (1996) Sverige och EMU. SOU 158, EMU-utredningen. Published in English as EMU: a Swedish perspective. (1997). Kluwer Academic Publishers, Dordrecht

Campos NF, Coricelli F, Moretti L (2013) Economic growth and European integration: a counterfactual analysis. Presented at AFSE Meeting June 24-26, 2013. Aix-en-Provence, France

De Grauwe P (2013) Design failures in the Eurozone: can they be fixed? LEQS Paper No. 57/2013

De Grauwe P, Ji Y (2015) Correcting for the Eurozone design failures: the role of the ECB. J Eur Integr 37(7):739754

De Grauwe P (2016) Economics of monetary union. Oxford University Press, Oxford

De Haan J, Inklaar R, Jong-A-Pin R (2008) Will business cycles in the euro area converge? A critical survey of empirical research. J Econ Surv 22(2):234-273

Durré A, Maddaloni A, Mongelli FP (2014) The ECB's experience of monetary policy in a financially fragmented euro area. Comp Econ Stud 56(3):396-423

Eichengreen B (1990) Costs and benefits of monetary union. CEPR Discussion Papers No. 453 
Faina JA, Lorenzo AG, Lopez-Rodriguez J, Montes-Solla P (2012) Effects of the Euro on foreign trade and growth in Spain. Paper produced within and part of the Jean Monnet Multilateral Research project

Feldstein M (1997) The political economy of the European economic and monetary union: political sources of an economic liability (No. w6150). National bureau of economic research Working Paper No. W6150

Frankel JA (2013) The future of the currency union. Harvard Kennedy School Working Paper Series No. RWP13-015

Frankel JA, Rose AK (1998) The endogeneity of the optimum currency area criteria. Econ J 108:1009-1025

Giavazzi F, Wyplosz C (2015) EMU: old flaws revisited. J Eur Integr 37(7):723-737

Gidehag R, Öhman H, Larsson S (2001) What has the EU done for us? Svenskt Näringsliv, Confederation of Swedish Enterprise

Giordano R, Pericoli M, Tommasino P (2013) Pure or wake-up-call contagion? Another look at the EMU sovereign debt crisis. Int Financ 16(2):131-160

Gomis-Porqueras P, Puzzello L (2015) Winners and losers from the Euro. (n. p)

Hannoun H (2011) Sovereign risk in bank regulation and supervision: where do we stand? Speech at the Financial Stability Institute High-Level Meeting, Abu Dhabi, UAE

Heckman J, Holz VJ (1989) Choosing among alternative nonexperimental methods for estimating the impact of social programs: the case of manpower training. J Am Stat Assoc 84(408):862-874

Maier P, Hendrikx M (2002) Implications of EMU enlargement for European monetary policy: a political economy view. Kredit und Kapital 36(2):137-166

Manasse P, Nannicini T, Saia A (2014) Italy and the euro: myths and realities. Retrieved from http://www. voxeu.org/article/italy-and-euro-myths-and-realities

Massmann M, Mitchell J (2004) Reconsidering the evidence: are eurozone business cycles converging? J Bus Cycle Meas Anal 1(3):275-307

Mazumder S, Pahl RM (2013) What if the UK had Joined the Euro in 1999? Open Econ Rev 24(3):447-470

Micco A, Ordonez G, Stein E (2003) Should Sweden join the EMU? Empirical trade evidence. Inter-American Development Bank. Retrieved from http://www.econ.yale.edu/ go49/pdfs/SWE_EMU_August_11.pdf

Mundell RA (1961) A theory of optimum currency areas. Am Econ Rev:657-665

Padoa-Schioppa T (1999) EMU and banking supervision. Int Financ 2(2):295-308

Pentecôte JS, Poutineau JC, Rondeau F (2015) Trade integration and business cycle synchronization in the EMU: the negative effect of new trade flows. Open Econ Rev 26(1):61-79

Pesaran MH, Smith LV, Smith RP (2007) What if the UK or Sweden had joined the Euro in 1999? An empirical evaluation using a Global VAR. Int J Financ Econ 12(1):55-87

Shelton C (2007) The size and composition of government expenditure. J Public Econ 91:2230-2260

Sinn H-W, Valentinyi A (2013) European imbalances. Retrieved from http://www.voxeu.org/article/europeanimbalances

Söderström U (2008) Re-evaluating Swedish membership in the EMU: evidence from an estimated model. NBER Working Paper 14519. National Bureau of Economic Research, Cambridge 